\title{
CORRELATION OF MEDICAL PROFESSIONALISM WITH ACADEMIC PERFORMANCE IN FINAL YEAR MEDICAL STUDENTS
}

\author{
Badar Murtaza, Abid Ashar*, Sohail Sabir* \\ Armed Forces Institute of Urology/National University of Medical Sciences (NUMS) Rawalpindi Pakistan, *College of Physicians and \\ Surgeons Pakistan, Karachi Pakistan
}

\begin{abstract}
Objective: To assess the correlation of medical professionalism score of final year medical students with their academic results of the final professional examination.

Study Design: Correlational study.

Place and Duration of Study: Army Medical College, Rawalpindi, from Mar to Nov 2019.

Methodology: Final year medical students were enrolled by non-probability consecutive sampling. Their medical professionalism score was calculated using the Penn State College of Medicine-Professionalism Questionnaire (PSCOM-PQ). All the aspects of accountability, altruism, excellence, duty, honour/integrity and respect were noted using the questionnaire. Thirty points from the questionnaire were used, calculating the maximum value of 150. After the final professional examination, their academic results were procured. The strength of the relationship between medical professionalism score and academic results of final year professional examination was assessed using the Pearson correlation coefficient.

Results: A total of 75 final year medical students were studied. The age ranged from 22-27 years $(23.96 \pm 1.16$ years). The male to female ratio was 2.12:1. The medical professionalism score ranged from 71-150 points (127.28 \pm 15.43 ). The academic results percentages of final year professional examination (MBBS) were not found to be significantly correlated with their professionalism score $(\mathrm{r}=-0.10, p=0.394)$.

Conclusion: The medical professionalism score of the final year medical students has no statistically significant correlation with their academic performance.
\end{abstract}

Keywords: Academic results, Medical professionalism, Medical students.

This is an Open Access article distributed under the terms of the Creative Commons Attribution License (http://creativecommons.org/licenses/by/4.0), which permits unrestricted use, distribution, and reproduction in any medium, provided the original work is properly cited.

\section{INTRODUCTION}

The word 'professionalism' is derived from the Latin word professioor public declaration. Though originally it referred to open declaration of a religious belief, the term is used to characterize the values, behaviour and attributes, apparent in individuals in the practice of a specific field. So, the abilities, skill, values and attributes expected from a doctor or a health worker can be considered as medical professionalism. According to the Accreditation Council for Graduate Medical Education (ACGME), professionalism is defined as 'manifested through a commitment to carrying out professional responsibilities, adherence to ethical principles and sensitivity to a diverse patient population' (ACGME 2004). Whit-

Correspondence: Dr Badar Murtaza, Classified Urologist, Armed Forces Institute of Urology, Rawalpindi Pakistan

Received: 20 Feb 2020; revised received: 03 Apr 2020; accepted: 13 Apr 2020 comb $\mathrm{ME}^{1}$, considered medical professionalism as a "keystone of the social contract between medicine and society at large".

Medical professionalism is a core competency for each and every medical practitioner. It can be illustrated as traits of accountability, altruism, excellence, duty, honour and integrity, and respect. As a generalization, all these values appear fundamentally important, however, these standards might not be exactly similar in all the societies. As a result, each society would require certain modifications and adaptations according to their perceptions. Teaching the students in the field of medical professionalism is not a straight forward modality. There is no specific and precise mode. The students may be trained through role-playing, mentoring, small group discussions and reflective writing 2 . However personal virtues, social responsibility, religion, punishment 
and reward may also contribute enormously. Effectively at present professionalism development is directly attributed to the hidden curriculum ${ }^{3}$.

Teaching professionalism is difficult but is achievable, however, assessing professionalism is even more difficult. This may be due to the subjectivity of the elements of professionalism and no single assessment tool can capture all elements. Clerkship evaluations, self-assessments, peer evaluations, $360^{\circ}$ evaluation and clinical encounters with simulated/standardized or actual patients can be used to assess the level of professionalism in the medical students. However the objective assessment of medical professionals can be conducted by various questionnaires including the Penn State College of Medicine-Professionalism Questionnaire (PSCOM-PQ) ${ }^{4}$. American Board of Internal Medicine (ABIM) Patient Assessment survey ${ }^{5}$, Barry's questionnaire and Professionalism Mini Evaluation Exercise $(p-\mathrm{MEX})^{6}$. Penn State College of Medicine-Professionalism Questionnaire (PSCOM-PQ) is a validated and reliable tool developed through an extensive development process.

A medical student reaching the final year should be at the peak of acquiring medical professionalism in a medical college. It is expected that students with better performance should also exhibit a higher level of professionalism. However, there is an apparent gapin the literature regarding the relationship between medical professionalism of medical students and their academic performance. No such study is available in the local literature, however, there is limited international data available on this aspect. Thus, this study aims to identify the correlation between the medical professionalism of the final year medical students and their academic results.

\section{METHODOLOGY}

This correlational study was conducted on the final year medical (MBBS) students of Army Medical College, Rawalpindi after the approval from the Ethics Review Board of Army Medical College, from March to November 2019. The data was collected in two phases. In the first phase, a questionnaire was formulated based on the Penn State College of Medicine Professionalism Questionnaire (PSCOM-PQ) ${ }^{4}$. Being a reliable, validated survey instrument, it is used to measure the attitudes towards professionalism among medical students, residents and the faculty members. The PSCOM-PQ is copyrighted to the Office of Medical Education, Pennsylvania State University College of Medicine. To use the PSCOM-PQ, a formal consent/ permission was taken through the email (gblackall@pennstatehealth.psu.edu) on 21 March 2018. After the focus group discussion of the panel of experts, the 36 points were reduced to 30, constituting accountability, altruism, duty, excellence, honesty/integrity and respect. The items were clear, understandable with a crisp conceptualization of the construct and those points of PSCOM-PQ were omitted which were related to the health care system and policy matters. By filling the questionnaire, a final year medical student was expected to rate the extent to which each item reflected his or her definition of professionalism. The rating was done on a fivepoint Likert scale (never, little, some, much and great deal) 4 and the total score was recorded out of 150. A total of 75 cases were selected according to the non-probability consecutive sampling. (Sample size was calculated by using the WHO calculator by keeping $\mathrm{r}=0.361$ fromthe study by Carr et $a l^{7}$ ). Strict confidentiality of the data was maintained and the inclusion of students was based on their voluntary participation with permission to withdraw at any time during the study (written informed consent was taken). However, there were no significant exclusion criteria. During this first phase of the study, the professionalism score of all the subjects was recorded.

In the second phase, these final year MBBS students' final professional examination results were collected from the examination office. The scores of the final professional examination were recorded and their percentages considered for the statistical analysis. Finally, all the data was entered electronically in a data collection form using the SPSS (Statistical package of social sciences) version 20 . The data included the ID number, age, 
gender, the score of professionalism questionnaire and the percentage ofthe final professional MBBS examination result. SPSS-20 was similarly used for correlation analysis between the total score of professionalism questionnaireand the academic performance in the final professional MBBS examination. The linear relationship between the two continuous variables was noted by Pearson's correlation and the statistical significance was calculated by the $p$-value $(<0.05$ was considered significant).

\section{RESULTS}

The 75 final year MBBS students included in this study had a mean age of $23.96 \pm 1.16$ years and $51(68 \%)$ of them were males while $24(32 \%)$ were females. The mean professionalism score was $127.28 \pm 15.43$, out of 150 , with a range of 71-150 (table-I). The percentage of the academic

Table-I: Participants profile.

\begin{tabular}{|c|c|c|c|c|}
\hline \multicolumn{3}{|c|}{ Variables } & \multicolumn{2}{|l|}{ Value } \\
\hline \multicolumn{3}{|c|}{ Age (years) } & \multicolumn{2}{|c|}{$23.96 \pm 1.16$} \\
\hline \multicolumn{5}{|c|}{ Gender } \\
\hline \multirow{2}{*}{\multicolumn{3}{|c|}{$\begin{array}{l}\text { Male } \\
\text { Female }\end{array}$}} & \multicolumn{2}{|c|}{$51(68 \%)$} \\
\hline & & & \multicolumn{2}{|c|}{$24(32 \%)$} \\
\hline \multicolumn{3}{|c|}{ Professionalism Score } & \multicolumn{2}{|c|}{$127.28 \pm 15.43$} \\
\hline \multicolumn{5}{|c|}{ professionalism score and academic results. } \\
\hline & \multicolumn{2}{|c|}{ Males $(n=51)$} & \multicolumn{2}{|c|}{ Females $(n=24)$} \\
\hline $\begin{array}{l}\text { Vari- } \\
\text { able }\end{array}$ & $\begin{array}{l}\text { Pearson } \\
\text { Correlation } \\
\text { Coefficientr }\end{array}$ & $\begin{array}{c}p- \\
\text { value }\end{array}$ & $\begin{array}{c}\text { Pearson } \\
\text { Correlation } \\
\text { Coefficientr }\end{array}$ & $\begin{array}{c}p- \\
\text { value }\end{array}$ \\
\hline $\mathrm{n}=75$ & 0.057 & 0.693 & -0.188 & 0.380 \\
\hline
\end{tabular}

results of final year professional examination (MBBS) showed a mean of $71.03 \pm 5.45$, ranging from $56.1-80.8 \%$. The study further revealed that overall academic results percentages of the final year professional examination (MBBS) were not significantly correlated (pearson correlation coefficient $\mathrm{r}=-0.10, p$-value 0.394) as evident from the scatter plot (figure).

Moreover, after stratifying based on the gender of the participants to control for its potential confounding effects, the correlation between professionalism score and results percentages were still not statistically significant in both males $(\mathrm{r}=$ 0.057, $p=0.693)$ and females $(r=-0.188, p=0.380)$.
Interestingly, although statistically insignificant, the correlation was found to be positive in males while negative in females (table-II).

\section{DISCUSSION}

The curriculum, teaching and assessment have a direct effect on the development of medical professionalism in students. However, there appears to be a deficiency in proper planning and implementation of a curriculum dedicated to the development of professionalism in medical and dental students. The hidden curriculum and its congruence with the students' attributes cannot be underestimated. The perception and interpretation of professionalism should be standardized in the minds of medical students and faculty members. Indeed the variance in the views of both the groups can have a different understanding in their thoughts ${ }^{8}$.

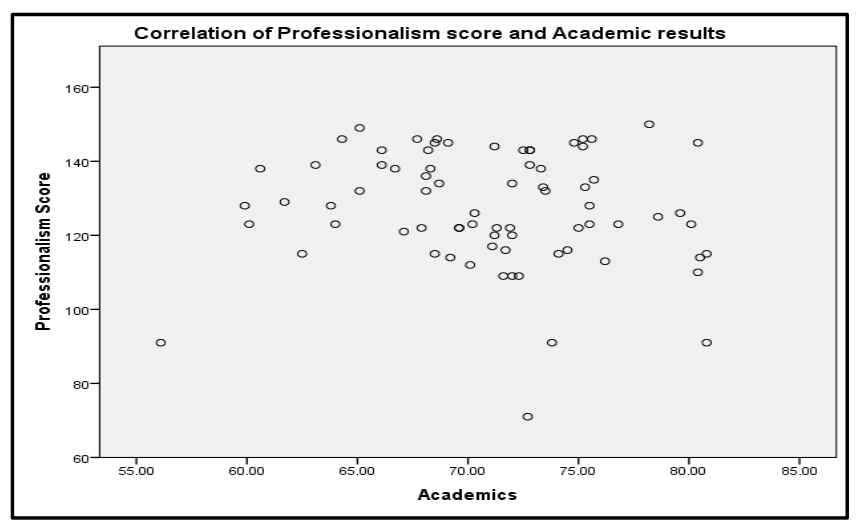

Figure: Scatter plot illustration of correlation between professionalism score and academic results.

As far as the medical students are concerned, they do express a lot of enthusiasm for 'serving the poor and needy patients and doing good to all'. But are they familiar with the principles of medical professionalism, the answer is usually: 'not a great deal'. Unfortunately in a local study conducted by Sobani et $\mathrm{al}^{9}$, on medical college students, the level and understanding of professional values were far below the acceptable level amongst the medical students. Indeed the students do not draw dissimilarity among the values commonly associated with professionalism. They foresee numerous problems associated with integrating values of altruism and dutifulness into 
their future practice of medicine. Khan et al10, reported that there are commonalities in the perceptions about the medical profession in the minds of medical practitioners, public and medical students, which are culturally and socio-economically significant.

In a study conducted at Missouri by Snider \& Johnson ${ }^{11}$, on osteopathic medical students, the professionalism score showed a positive association with the final grade/grade point average (GPA) of the students. They also found a statistically significant difference in the scores of the first and second-year students. Likewise, Razzaq et $a l^{12}$, reported a positive correlation in the paediatric residents showing an increase in the perception of their professional behaviours with increasing years of training. Similar results were documented by an Egyptian study by Salem et al13, on residents and by a Japanese study on hospital staff by Tsugawa et al ${ }^{14}$. However in this study we did not find a statistically significant correlation of the professionalism score with the academic results in the final year medical students $(\mathrm{r}=-0.10, p=0.394)$. Interestingly slight positive correlation was seen in the males as compared to the female students. In another study with slightly similar results, Akhund et al15, rated that the attributes of professionalism as important but found no significant difference in the elements of professionalism mean scores or in the overall mean scores of professionalism in the various classes of Pakistani and Pakistani heritage medical students. While in an interesting study, Papadakis et al16, reported association of academic results with the professional attitudes. They documented that medical students with unprofessional behaviours in the medical school were connected with late disciplinary actions. Secondly, the medical practitioners who had discipline issues in the medical boards had lesser GPAs during their medical school period. Likewise, Chew et al17, and Fernandez et al ${ }^{18}$, also reported that the students with greater GPAs had favourable professional attitudes and even superior clerkship appraisals. Khadija et al ${ }^{19}$, used the professionalism assessment scale (PAS) for comparing the first and final year students. They reported that the latter group had a high rate of all the elements of the questionnaire. Carr et al7, found a significant correlation between the academic performance of medical students and their workplace performance as junior doctors. But our study failed to show such an association.

The inference that we can draw from our study is that the good high scoring students may not necessarily have a higher level of professionalism and vice versa. Indeed this directs us to the fact that our curriculum does not cater to this essential part ofthe training. Our undergraduate training program needs to be modified with the inclusion of essential professionalism curriculum along with the introduction of assessment modalities of medical professionalism in our future doctors. Most of the medical councils and the regulatory bodies do approve that professionalism, as well as the medical ethics, should be imparted to the undergraduate students, but this can be commonly seen in the medical colleges of Europe and US, whereas in an underdeveloped country like ours the awareness is growing but the practical steps are still awaited ${ }^{20}$. Indeed the curriculum, the hidden curriculum and culture influence the medical students' perception of professiona$\operatorname{lism}^{21}$, while the social learning interventions also assist in strengthening the attitudes towards professionalism in the medical students ${ }^{22}$. Hojat et $a l 23$, reported that in medical students, empathy was associated with the core clinical competencies but not with the objective examinations of MCAT (Medical College admission test) and USMLE (US Medical Licensing Examination). Its importance can be realized from the fact that Waheed et al24, even proposed that the medical colleges should include some form of assessment regarding aptitude of professionalism in the admission process to identify future medical students' capacity for professional behaviour.

Role modelling has a deep impact on the students' thoughts and behaviour. All teachers must emphasize being rolemodels for their pupils, as the latter consider them as the icons of professionalism ${ }^{25}$. The young minds coopt and 
further circulate the designs and manners that are modelled to them. The ineffective role models are even more essential, as displaying ineptitude, negative behaviours and immoral approaches may present examples to the students who are not to be followed or promulgated. However, another dictum is considered that professionalism should be "taught" in addition to being "caught" in the role models. Some experts maintain professionalism should be taught overtly during medical training using definitions or list of professional traits, and then be reinforced through experiential learning. Measurement of professionalism is an important part of investigating and teaching medical professionalism. There are numerous components of professionalism, our medical colleges and working environments should cater to these optimal methods of teaching medical professionalism.

\section{CONCLUSION}

The medical professionalism score in the final year medical students does not correlate with their academic performance. This indicates possible implications of an absence of professionalism curriculum and highlights an area to develop in medical undergraduate training.

\section{CONFLICT OF INTEREST}

This study has no conflict of interest to be declared by any author.

\section{REFERENCES}

1. Whitcomb ME. Professionalism in medicine. Acad Med 2007; 82(11): 1009-12.

2. O'Sullivan $\mathrm{H}$, van-Mook $\mathrm{W}$, Fewtrell $\mathrm{R}$, Wass $\mathrm{V}$. Integrating professionalism into the curriculum: AMEE Guide No. 61. Med Teach 2012; 34(2): e64-e77.

3. Ashar A, Ahmad A. Developing professionalism: dental students' perspective. J Coll Phys Surg Pak 2014; 24(12): 902-07.

4. Blackall GF, Melnick SA, Shoop GH, George J, Lerner SM, Wilson PK. Professionalism in medical education: The development and validation of a survey instrument to assess attitudes toward professionalism. Med Teach 2007; 29(2): e58-e62

5. Symons AB, Swanson A, Mc Guigan D, Orrange S, Akl EA. A tool for self-assessment of communication skills and professionalism in residents. BMC Med Educ 2009; 9(1): 1-5.

6. Cruess R, Mcllroy JH, Cruess S, Ginsburg S, Steinert Y. The professionalism mini-evaluation exercise: a preliminary investigation. Acad Med 2006; 10(1); S74-S78.

7. Carr SE, Celenza A, Puddey IB, Lake F. Relationship between academic performance of medical students and their workplace performance as junior doctors. BMC Med Educ (Internet) 2014; 14(1): 157-60.

8. Sattar K, Roff S, Meo SA. Your professionalism is not my professionalism: congruence and variance in the views of medical students and faculty about professionalism. BMC Med Educ 2016; 16(285): 1-7.

9. Sobani ZA, Mohyuddin MM, Farooq F, Qaiser KN, Gani F. Professionalism in medical students at a private medical college in Karachi, Pakistan. J Pak Med Assoc 2013; 63(7): 935-39.

10. Khan JS, Tabasum S. Medical professionalism: A panoramic view through the kaleidoscope of stakeholder perspectives. J Ayub Med Coll Abbottabad 2011; 23(3): 138-44.

11. Snider KT, Johnson JC. Professionalism score and academic performance in osteopathic medical students. J Am Osteopath Assoc 2014; 114(11): 850-59.

12. Razzaq A. Measuring professionalism in postgraduate paediatric residents using professionalism mini-evaluation exercise (PMEX). Pak Arm For Med J 2019; 69(4): 784-88.

13. Salem A, Talaat W, Kamel MH, Hassan N. Assessing Professionalism among Residents: Peer and Self-assessment. Intel Prop Rights 2015; 3(1): 148-53.

14. Tsugawa $Y$, Ohbu S, Cruess R, Cruess S, Okubo T, Takahashi $\mathrm{O}$, et al. Introducing the Professionalism Mini-Evaluation Exercise (P-MEX) in Japan: Results from a multicenter, Cross-sectional study. Acad Med 2011; 86(8): 1026-31.

15. Akhund S, Shaikh ZA, Ali SA. Attitudes of Pakistani and Pakistani heritage medical students regarding professionalism at a medical college in Karachi, Pakistan. BMC Research Notes 2014; 7(2): 150-52.

16. Papadakis MA, Hodgson CS, Teherani A, Kohatsu ND. Unprofessional behavior in medical school is associated with subsequent disciplinary action by a state medical board. Acad Med 2004; 79(3): 244-49.

17. Chew BH, Zain AM, Hassan F. Emotional intelligence and academic performance in first and final year medical students: a cross-sectional study. BMC Med Educ 2013; 13(1): 44-46.

18. Fernandez R, Salamonson Y. Emotional intelligence as a predictor of academic performance in first-year accelerated graduate entry nursing students. J Clin Nurs 2012; 21(23-24): 3485-92.

19. Khadija Q, Shah SAH, Aziz MA. Refining elements of medical professionalism in the undergraduate medical students. Pak Arm For Med J 2016; 66(1): 151-56.

20. Shukr I. Defining medical professionalism and academic integrity. A function of medical councils and medical colleges. Pak Arm For Med J 2014; 64(2): 181-84.

21. Al-Abdulrazzaq D, Al-Fadhli A, Arshad A. Advanced medical students' experiences and views on professionalism in Kuwait university. BMC Med Educ 2014; 14(1): 150-52.

22. Selic P, Cerne A, Klemenc-Ketis Z, Petek D, Syab I. Attitudes towards professionalism in medical students and its association with personal characteristics and values: a national multicenter study from Slovenia raising the question of the need to rethink professionalism. Adv Med Educ Prac 2019; 10(1): 437-46.

23. Hojat M, Gonella JS, Mangione S, Nasca TF, Veloski FF. Empathy in medical students as related to academic performance, clinical competence and gender. Med Educ 2002; 36(6): 522-27.

24. Waheed G, Mengal MA. Faculty and students' perception about aptitude of professionalism in admission process of medical college. J Ayub Med Coll Abbottabad 2011; 23(2): 166-69.

25. Kebede S, Gebremeskel B, Yekoye A. Medical professionalism: perspectives of medical students and residents at Ayder Comprehensive and Specialized Hospital, Mekelle, Ethiopia-a crosssectional study. Adv Med Educ Pract 2018; 9(1): 611-16. 